pp 1631-1653. (C) The Author(s), 2021. Published by Cambridge University Press on behalf of Royal Aeronautical Society. This is an Open Access article, distributed under the terms of the Creative Commons Attribution licence (http://creativecommons.org/licenses/by/4.0/), which permits unrestricted re-use, distribution, and reproduction in any medium, provided the original work is properly cited.

doi:10.1017/aer.2021.3

\title{
Multi-platform app-embedded model for hybrid air-breathing rocket-cycle engine in hypersonic atmospheric ascent
}

\author{
S.E. Tsentis $(\mathbb{D})$, V.G. Gkoutzamanis $(\mathbb{D})$ A.D. Gaitanis and A.I. Kalfas $(\mathbb{D})$ \\ tsentise@meng.auth.gr \\ Department of Mechanical Engineering \\ Laboratory of Fluid Mechanics and Turbomachinery \\ Aristotle University of Thessaloniki \\ Thessaloniki \\ GR 54124 \\ Greece
}

\section{ABSTRACT}

This paper presents a performance analysis on a novel engine concept, currently under development, in order to achieve hybrid air-breathing rocket technology. A component-level approach has been developed to simulate the performance of the engine at Mach 5, and the thermodynamic interaction of the different working fluids has been analysed. The bypass ramjet duct has also been included in the model. This facilitates the improved evaluation of performance parameters. The impact of ram drag induced by the intake of the engine has also been demonstrated. The whole model is introduced into a multi-platform application for aeroengine simulation to make it accessible to the interested reader. Results show that the bypass duct modelling increases the overall efficiency by approximately $7 \%$. The model calculates the specific impulse at approximately 1800 seconds, which is 4 times higher than any chemical rocket.

Keywords: component modeling; cycle analysis; performance simulation; multi-platform application

\section{NOMENCLATURE}

\section{Symbols}

$C_{p} \quad$ Specific heat at constant pressure $\left(\mathrm{kJ} \mathrm{kg}^{-1} \mathrm{~K}^{-1}\right)$

$D \quad \operatorname{Drag}(k N)$

$f \quad$ Fuel-to-air ratio of bypass duct

F Thrust $(k N)$ 


$\begin{array}{ll}H & \text { Enthalpy }\left(\mathrm{kJ} \mathrm{kg}^{-1}\right) \\ I_{s p} & \text { Specific impulse }(\mathrm{s}) \\ M & \text { Mach number } \\ \dot{m} & \text { Mass flow rate }\left(\mathrm{kg} \mathrm{s}^{-1}\right) \\ P & \text { Static pressure }(\text { bar }) \\ \dot{Q} & \text { Heat transfer rate }(\mathrm{W}) \\ S & \text { Entropy }\left(\mathrm{kJ} \mathrm{kg}^{-1} \mathrm{~K}^{-1}\right) \\ T & \text { Static temperature }(\mathrm{K}) \\ V & \text { Velocity }\left(\mathrm{m} \mathrm{s}^{-1}\right) \\ \Delta P & \text { Pressure difference }(\text { bar }) \\ \Delta T & \text { Temperature difference }(K)\end{array}$

\section{Subscripts}

$\begin{array}{ll}\text { amb } & \text { Ambient } \\ \text { comb } & \text { Combustion } \\ \text { exbp } & \text { Exit from bypass } \\ \mathrm{H}_{2} & \text { Hydrogen } \\ \mathrm{He} & \text { Helium } \\ \text { in } & \text { Inlet } \\ \text { inf } & \text { Infinite stream conditions } \\ n 1 & \text { Normal Mach number before oblique shock wave } \\ n 2 & \text { Normal Mach number after oblique shock wave } \\ o & \text { Overall } \\ \text { obl } & \text { Conditions after oblique shock wave } \\ \text { out } & \text { Outlet } \\ p & \text { Propulsive } \\ t h & \text { Thermal }\end{array}$

\section{Greek Symbols}

$\beta \quad$ Oblique shock wave angle ( $\mathrm{deg})$

$\gamma \quad$ Ratio of specific heats

$\delta \quad$ Error

$\eta \quad$ Efficiency

$\theta \quad$ Half the angle of intake cone (deg)

$\Pi \quad$ Compression ratio

\section{Abbreviations}

AirC Air compressor

BB Bypass burners

$\mathrm{CC}$ Combustion chamber

CD Convergent - Divergent 


$\begin{array}{ll}\text { HeC } & \text { Helium circulator } \\ \text { HeT } & \text { Helium turbine } \\ \text { HT1 } & \text { Hydrogen turbine number } 1 \\ \text { HT2 } & \text { Hydrogen turbine number } 2 \\ \text { HX3 } & \text { Heat exchanger number } 3 \\ \text { HX4 } & \text { Heat exchanger number } 4 \\ \text { LEO } & \text { Low earth orbit } \\ \text { LHP } & \text { Liquid hydrogen pump } \\ \text { LHT } & \text { Liquid hydrogen tank } \\ \text { PB } & \text { Pre-burner } \\ \text { PC } & \text { Pre-cooler } \\ \text { PRV } & \text { Pressure ratio valve } \\ \text { RBCC } & \text { Rocket-based combined cycle } \\ \text { RLV } & \text { Reusable launch vehicle } \\ \text { SABRE } & \text { Synergetic air-breathing rocket engine } \\ \text { SFC } & \text { Specific fuel consumption } \\ \text { SSTO } & \text { Single-stage-to-orbit } \\ \text { TBCC } & \text { Turbine-based combined cycle }\end{array}$

\section{Trade Names}

$\begin{array}{ll}\text { AeroEngineS } & \text { Multi-platform application for aeroengine simulation } \\ \text { JavaScript } & \text { text-based programming language } \\ \text { MATLAB } & \text { Programming environment } \\ \text { NASA } & \text { National Aeronautics and Space Administration } \\ \text { REL } & \text { Reaction Engines Limited } \\ \text { SpaceX } & \text { Space Exploration Technologies Corporation }\end{array}$

\subsection{INTRODUCTION}

The technical and commercial feasibility of reusable single-stage-to-orbit (SSTO) vehicles, as well as hypersonic aircrafts, is being considered for many years, worldwide. Several engine types have been investigated to fit the missing parts of such concepts. The air-breathing engines that may be suitable and allow propulsion up to hypersonic speeds are ramjets, scramjets, turbojets or a combination of them ${ }^{(1)}$. These choices, however, impose major limitations for both SSTO reusable launch vehicles (RLV) and hypersonic aircrafts.

Ramjets are much more simple devices, from a thermodynamic point of view ${ }^{(2)}$, compared to any other air-breathing engine. However, ramjet engines are not capable of achieving the aforementioned missions since they cannot produce static thrust and thus cannot propel an aircraft or spaceplane from a standstill. A scramjet engine can achieve much higher Mach numbers compared to a ramjet engine, but still cannot produce static thrust. Additionally, it is one of the most demanding and complex engine concepts from an engineering perspective ${ }^{(3-5)}$. Turbojets and the engines that employ onboard work transfer to the airflow are capable of operation from a standstill. This is a major advantage over engines 
employing solely ram compression. However, turbojets have a rapid thrust decay above Mach 3 due to the rise of the inlet temperature forcing a reduction in pressure ratio. In addition to this, at speeds greater than Mach 2.5, the temperature prior to compression is very high to be handled by the turbomachinery parts. Therefore, turbojets are limited in terms of their operational Mach range ${ }^{(6)}$.

Several engine concepts of hybrid air-breathing rocket technology have been developed over the years of aviation and space missions. The main concepts are combinations of the airbreathing engines mentioned above and rocket technology. These include the turbine-based combined cycle engines (TBCC), which combine turbine engines with ramjet or scramjet technology. The rocket-based combined cycle engines (RBCC), which combine ramjet or scramjet with rocket technology, are also included ${ }^{(7)}$. Both concepts face high technical difficulties for mode conversion and thermal protection during hypersonic flight. Cooling the air in advance is considered an effective way to address this difficulty.

Hybrid precooled air-breathing combined cycle engines, which are the main focus of this study, have been rapidly developed to enable reusable vehicles ${ }^{(8)}$. They extend the operating range of turbomachinery by cooling the air upstream of the compressor ${ }^{(9-11)}$. By pre-cooling the air, the pressure ratio can be very high without hitting the spool speed or material limits. In this way the engine can safely operate from sea level static conditions up to around Mach 5 in the air-breathing mode. Beyond this speed, the cone of the intake moves forward to block the airflow completely. The engine utilises onboard liquid oxygen, and the operation is similar to a rocket system, providing the thrust needed to achieve orbital velocities. Additionally, since high-pressure ratios are achieved in the air-breathing mode, the same combustion chamber and nozzle can be used in both air-breathing and rocket modes, reducing the system mass. At present, the hybrid precooled combined-cycle engine is considered as one of the key technologies for achieving SSTO reusable vehicles.

This type of engine has attracted wide attention mainly in terms of its application. The use of this engine to power an SSTO aircraft-like spaceplane has been widely reported in the open literature with detailed descriptions for both the technical and financial aspects of the mission ${ }^{(12-16)}$. Furthermore, the development status of such engines is reported in the literature. However, it is mainly focused on the progress of the pre-cooler and other key technologies, as well as the infrastructure of the RLV to be equipped with these engines $^{(9,10,17-23)}$.

Additionally, some of the literature emphasises on the concept of the engine only ${ }^{(16,24,25)}$, and very few analytical calculations are presented ${ }^{(26-28)}$. Few simulation models have been developed $^{(28,29)}$ for hypersonic combined-cycle propulsion systems, based on performance simulating software. Also, exergy analysis of similar engine concepts has been reported, and cycle efficiency has been evaluated ${ }^{(29-31)}$. In general, performance calculations of such engines are very few in the public literature and the bypass of the engine, as well as the inlet ram drag, are usually neglected.

In this paper, the performance analysis on a novel hybrid air-breathing rocket engine at design point is presented. It is inspired by the engine concept of Synergetic Air-Breathing Rocket Engine (SABRE), currently under development. The model developed in this study accounts for the bypass duct, as well as intake ram drag. The importance of some key working parameters is presented, via an error propagation analysis. The model is embedded into a multi-platform application to be made widely available and exposed to the interested reader. Finally, a preliminary cost analysis for an RLV is conducted to review the viability of such concepts. However, during this study, it became obvious that this engine has numerous other applications and could play a significant role in the future aerospace industry. 


\subsection{METHODOLOGY}

\subsection{Core engine configuration}

The engine under investigation is a hybrid air-breathing rocket engine composed of the core engine and the bypass burners which are placed circumferentially around the core nozzle. The present study focuses on both parts of the engine. The core engine is mainly composed of the intake, pre-cooler, compressor, turbine, combustion chamber and nozzle. As shown in Fig. 1, a closed Brayton cycle between air and liquid hydrogen is introduced, with helium as the medium. The air temperature after the inlet shock wave compression exponentially increases with the increase in flight Mach number, hence the introduction of cooling is essential for the successful operation of the engine. At design point, which is at an altitude of $25 \mathrm{~km}$ and a flight speed of Mach 5, the air temperature after the shock waves is approximately $1200 \mathrm{~K}^{(32)}$. After the primary compression in the intake, the airflow gets deeply cooled down to temperatures of $120 \mathrm{~K}$ by the intermediate cycle of helium in the pre-cooler (PC). The airflow is then directed through the air compressor (AirC) to further raise its pressure to a level similar to that of a rocket combustion chamber at approximately 150 bar.

After the compression in the AirC, the airflow is separated into two portions. One portion is fed into pre-burner (PB) where the compressed air reacts with the liquid hydrogen fuel. The combustion products are used in heat exchanger number 3 (HX3) to heat the helium up to a steady temperature in order to supply the helium turbine (HeT) with constant working conditions. The other portion is fed directly to the main combustion chamber (CC) to react with the fuel-rich products from the PB. Liquid hydrogen is pumped from the tank (LHT) into number 4 heat exchanger (HX4) via a conventional centrifugal liquid hydrogen pump (LHP). At HX4 the liquid hydrogen is heated and vaporised, then drives the turbines number 1 (HT1) and number 2 (HT2) before entering the PB at about 600K. After the energy transfer at HX3, helium drives the HeT and then is cooled down to its initial temperature by the cold liquid hydrogen at HX4. Thereafter, a pressure ratio valve (PRV) controls the pressure of helium in order to provide steady pressure to the helium circulator $(\mathrm{HeC})$ to allow for a new cycle to start over.

The cycle configuration as used to model the core engine is shown in Fig. 1. The intermediate closed Brayton cycle of helium is introduced in the engine in order to make use of the heat extracted from the air at the pre-cooler. It also works as a barrier between the hot air and the liquid hydrogen.

\subsection{Core component-level modeling}

A component-level model, based on the cycle illustrated in Fig. 1, is developed in a modern programming environment (MATLAB) to evaluate the performance of the core engine. The energy conservation principles are applied for each component of the cycle and integrated through a system of equations. Several parameters of the core engine operation at the design point, in terms of temperatures and pressures, are necessary for the modeling and are extracted from the publicly available data ${ }^{(33)}$. The mass flow rates of the working fluids, as well as the temperature and pressure of every station, are the main variables calculated. This enables the performance of the engine to be evaluated. The model is an iterative process, which calculates 


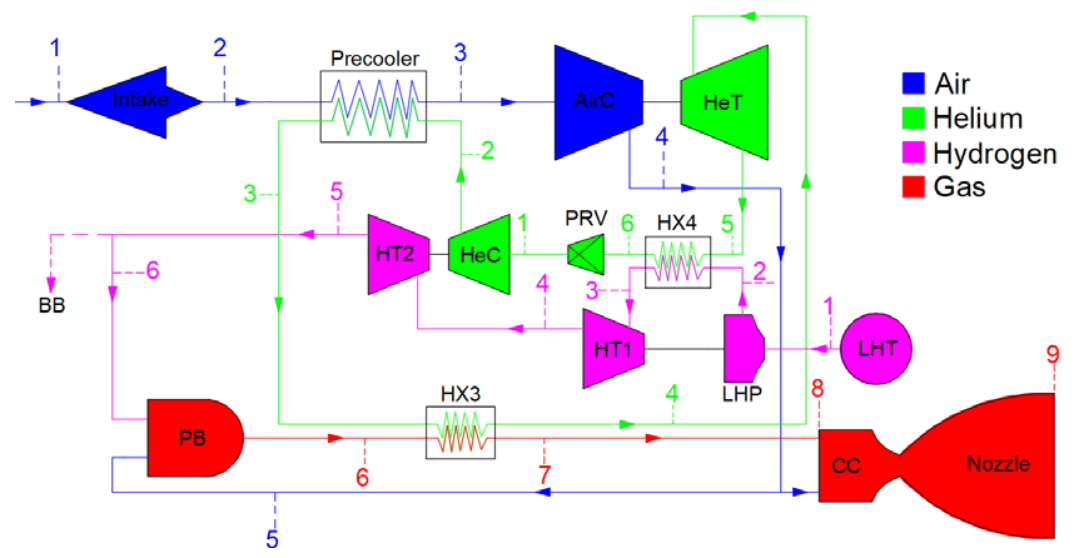

Figure 1. Thermodynamic cycle of the engine core ${ }^{[11,29]}$.

the operating parameters of the core engine for every station of each working fluid until the net thrust produced, reaches a certain value.

The following operating conditions are considered in this study:

- The helium outlet temperature of PC is limited to $950 \mathrm{~K}$ due to material temperature limitations ${ }^{(9,10,21)}$.

- The pressure ratio of AirC is derived based on the air outlet pressure after the compression, which is set to $145 \operatorname{bar}^{(8)}$.

- The pressure of He entering the PC is approximately 200 bar $^{(21,35)}$.

- The helium inlet temperature of HeT remains constant through the whole air-breathing ascent at a value of $1080 \mathrm{~K}^{(28,29)}$.

- The targeted net thrust at a flight speed of Mach 5 and an altitude of $25 \mathrm{~km}$ is set to $1050 \mathrm{kN}^{(8,29,33)}$.

\subsubsection{Intake}

The intake of the engine constitutes of a cone which angle is set to 40 degrees. When the engine reaches speeds over Mach 1, a dual shock wave system appears at the inlet. This system remains at a constant position throughout the whole air-breathing ascent through the movement of the cone. The ambient pressure and temperature are calculated by the flight altitude and Mach number. Considering the air compression at the intake an adiabatic process and given the flight Mach number, the Mach number at the end of the shock wave system, as well as the temperature and pressure, can be calculated using the analytical shock waves equations. Thus, the parameters of the airflow past the normal shock wave can be obtained accurately as a function of flight Mach number. Equations (1-3) give static pressure and temperature, as well as the Mach number after the shock wave system, as calculated in this study ${ }^{(34)}$.

$$
\left\{\begin{array}{c}
M_{n 1}=M_{1} \cdot \sin (\beta) \\
M_{n 2}=\sqrt{\frac{1+\frac{\gamma-1}{2} \cdot M_{n 1}^{2}}{\gamma \cdot M_{n 1}^{2}-\frac{\gamma-1}{2}}}
\end{array}\right.
$$




$$
\begin{gathered}
\Rightarrow\left\{\begin{array}{c}
M_{o b l}=\frac{M_{n 2}}{\sin (\beta-\theta)} \\
P_{o b l}=P_{1} \cdot\left[1+\frac{2 \cdot \gamma}{\gamma+1} \cdot\left(M_{n 1}^{2}-1\right)\right] \\
T_{o b l}=T_{1} \cdot \frac{\left(2+(\gamma-1) \cdot M_{n 1}{ }^{2}\right)}{(\gamma+1) \cdot M_{n 1^{2}} \cdot\left(1+\frac{2 \cdot \gamma}{\gamma+1}\right) \cdot\left(M_{n 1^{2}}{ }^{2}-1\right)} \\
M_{2}=\sqrt{\frac{1+\frac{\gamma-1}{2} \cdot M_{o b l}{ }^{2}}{\gamma \cdot M_{o b l}{ }^{2}-\frac{\gamma-1}{2}}} \\
P_{2}=P_{o b l} \cdot\left[1+\frac{2 \cdot \gamma}{\gamma+1} \cdot\left(M_{o b l}{ }^{2}-1\right)\right] \\
T_{2}=T_{o b l} \cdot \frac{\left(2+(\gamma-1) \cdot M_{o b l}{ }^{2}\right)}{(\gamma+1) \cdot M_{o b l}{ }^{2} \cdot\left(1+\frac{2 \cdot \gamma}{\gamma+1}\right) \cdot\left(M_{o b l}{ }^{2}-1\right)}
\end{array}\right.
\end{gathered}
$$

The angle $\beta$ is determined by the angle $\theta$ of the intake cone and the flight Mach number. The conditions at Eq. (2) are referring to the station between the oblique and the normal shock wave. Equations (1-3) are evaluated by comparing the results regarding the air temperature after the normal shock wave, which is the temperature prior to $\mathrm{PC}$, to the data from references $^{(11,32)}$.

\subsubsection{Heat exchangers}

The analytical calculation of the parameters of the heat exchangers, in terms of heat transfer and pressure drop, is not the main focus of this study. Thus, for the pre-cooler, a pressure drop of about 0.5 bar is assumed based on the literature ${ }^{(35)}$ and the conservation of energy transferred between helium and air is applied. The performance of heat exchangers number 3 and 4 is calculated in the same way. The pressure drop in these heat exchangers is neglected. This is because the similar pressure levels of the working fluids in these heat exchanges, as well as their compact design, is expected to give acceptable pressure losses ${ }^{(9,35)}$. The governing equation of the heat exchangers, as implemented in this study, is described by Eq. (4) where ideal energy transfer is assumed. This approach would be more accurate if a factor was introduced in the equation to account for practical limitations in the heat exchangers design and should be considered in future work.

$$
\dot{Q}_{\text {hot }}=\dot{Q}_{\text {cold }} \Rightarrow\left(\dot{m} \cdot C_{p} \cdot \Delta T\right)_{h o t}=\left(\dot{m} \cdot C_{p} \cdot \Delta T\right)_{\text {cold }}
$$

\subsubsection{Turbomachinery}

The HeT drives the AirC; therefore, the work of the two turbomachines is approximately the same. Given the fact that the engine is still under development, the mechanical efficiency remains unknown. In this paper, a mechanical efficiency of 0.99 is assumed based on other turbomachinery applications in civil aviation ${ }^{(2,45)}$. A similar approach is adopted for the other pairs of turbines and compressors of the core engine. The pressure ratio of the AirC is determined by the CC pressure level needed for rocket operation. The isentropic equations of 


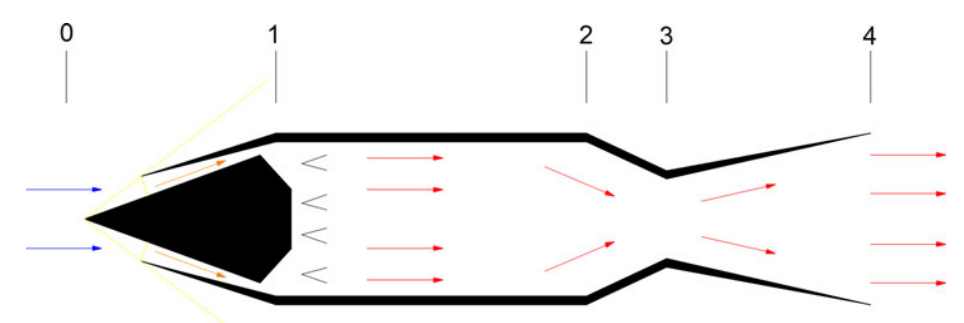

Figure 2. Ramjet engine schematic.

turbomachinery are also included in the system to calculate the pressure and temperature at different stations, using an isentropic efficiency to account for losses.

\subsubsection{Combustion chambers}

The operating parameters before and after the PB and CC are calculated by the system equations, and no analytical calculation for the combustion process is used in this study. This is to reduce the amount of time needed to simulate the performance of the engine. Additionally, a more accurate method to obtain these parameters is expected to have a minor effect on the overall engine performance. The combustion efficiency used is 0.95 , and the pressure drop at the $\mathrm{PB}$ is assumed to be $15 \%$ due to injection phenomena. The pressure drop in the $\mathrm{CC}$ is neglected, based on the assumption of isobaric combustion.

\subsubsection{Nozzle}

A conventional bell nozzle, normally used in rocket systems, is employed in this analysis in order to calculate the exit parameters of the engine core. The design point is assumed to be the optimal operating condition for the nozzle so that the exit pressure is equal to the ambient and the nozzle is not under or over expanded. The nozzle performance is thus calculated based on the adiabatic equilibrium assumption. Friction and boundary layer losses are ignored and gases do not change their composition during the expansion process.

\subsubsection{Other systems}

Several other components are important for the operation of the engine such as the PRV and LHP. The PRV is used in the cycle to adjust the pressure of helium, in order to be maintained constant and provide steady state operating conditions to the HeC. Temperature losses caused by the PRV are expected to be minor and are neglected. Liquid hydrogen is pumped via LHP, which is considered a conventional centrifugal pump, normally used for rocket engines, with high pressure ratio and stored in LHT at liquefaction conditions.

\subsection{Bypass ramjet component-level modeling}

The bypass duct of the engine is also modeled. This facilitates the improved evaluation of performance parameters of the hybrid air-breathing rocket engine in the hypersonic atmospheric ascent. The bypass duct of this engine is a pure ramjet engine and the model is based on ramjet equations neglecting, at first, some connections with the core engine. Figure 2 illustrates the schematic and the stations of the ramjet engine as it is used in this modeling.

An intake system, where one oblique and one normal shock wave appears, is adopted. Inlet conditions are similar to the hybrid engine under investigation, rather than any ramjet 
engine. The shock waves system is depicted in Fig. 2. The model calculates the performance parameters of the ramjet engine, as well as the static and total pressures and temperatures at every station as shown in the engine schematic.

\subsubsection{Bypass intake}

The intake shock wave system is calculated in the same way as for the core engine, since the two engines share the same intake geometry.

\subsubsection{Bypass combustion process}

Since there is no downstream turbine, a ramjet combustor can safely operate at stoichiometric fuel-to-air ratios. This implies a combustor exit stagnation temperature of the order of $2,200 \mathrm{~K}$. Additionally, a pressure loss of $5 \%$ is used to account for some pressure drop during the combustion process, based on other typical ramjet engines. These conditions are described by Eq. (5).

$$
\left\{\begin{array}{l}
P_{2}=P_{1}-\Delta P_{c o m b} \\
\Delta P_{c o m b}=0.05 \cdot P_{1} \\
f=0.035
\end{array}\right.
$$

\subsubsection{Bypass nozzle}

At the exit of the engine, the airflow gets expanded through the nozzle. In this study, it is assumed that the nozzle expands the gas ideally, but suffers from a total pressure drop of $\Pi_{\mathrm{n}}=0.92$. Moreover, the altitude is considered to be the design point for the nozzle, thus the pressure at the exit is equal to that of the atmosphere. The model calculates the specific thrust produced by the ramjet engine as illustrated by Eq. (6) as well as other performance parameters (e.g. SFC, Isp, $\eta_{\mathrm{p}}, \eta_{\mathrm{th}}, \eta_{\mathrm{o}}$, etc. $)^{(2)}$.

$$
\frac{F_{n e t}}{\dot{m}_{o}}=(1+f) \cdot V_{e x b p} \cdot\left[1+\frac{1}{\gamma \cdot M_{e x b p}^{2}} \cdot\left(1-\frac{P_{0}}{P_{4}}\right)\right]-V_{i n f}
$$

\subsection{Model integration}

The model of the core engine is adjusted to the conditions and operating parameters of the engine under investigation, the hybrid air-breathing rocket engine. However, the ramjet engine model provides the performance of a ramjet engine with only few similar characteristics to the engine under investigation (e.g. the intake system). Further adjustments are needed in order to integrate it to the whole engine model. The integration is achieved through the introduction of some key working parameters of the core engine model to that of the ramjet engine. The key parameters are the flight Mach number and altitude, as well as the amount of liquid hydrogen diverted from the core to the BB (bypass burners). This point is located between stations number 5 and 6 of the hydrogen cycle (Fig. 1.). It is assumed that the diverted amount of liquid hydrogen is $15 \%$ of the total amount of fuel needed to achieve the targeted net thrust. In this way, the ramjet engine is adjusted to the core engine in order to produce an integrated model with improved accuracy. The engine composed of both the core and bypass is shown in Fig. 3, and the integrated engine model is based on this configuration. 


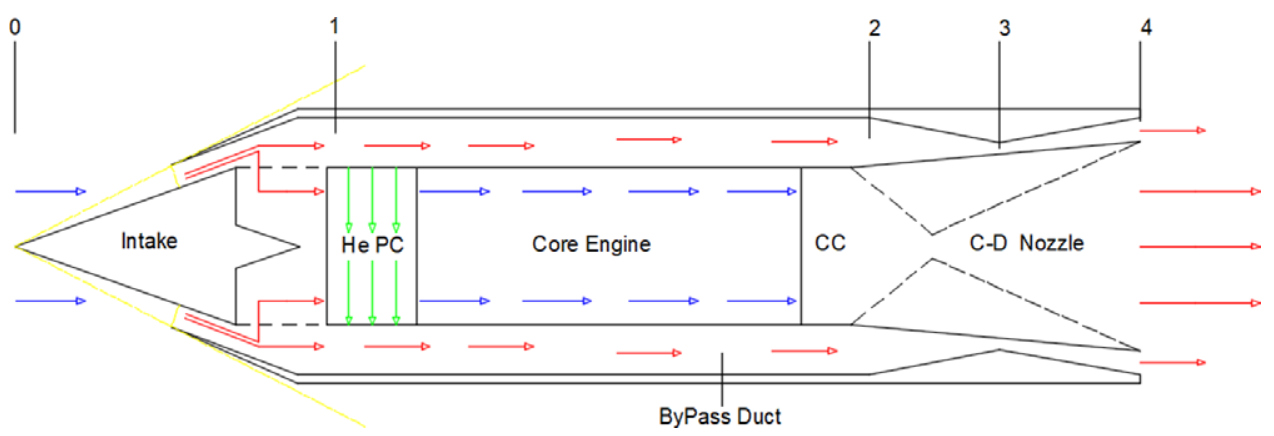

Figure 3. Engine schematic in air-breathing mode.

The core engine is supplied with more liquid hydrogen than what is needed for combustion. The excess amount of cold hydrogen is required for the cooling of helium at HX4, which is at very high temperatures as it provides the cooling of the incoming air. The amount of liquid hydrogen, not needed for combustion, is diverted to the BB before it goes to the PB. At lower flight Mach numbers less hydrogen is required for cooling, thus more going into the $\mathrm{BB}$, so the bypass produces more thrust. Also, the bypass is making use of the excessive airflow which cannot pass to the core engine and would induce extra drag. Therefore, the bypass duct is designed to exploit the excessive amounts of hydrogen and air, depending on the flight segment and Mach number. At the same time, it contributes to the overall thrust, and so it improves the performance and the efficiency of the engine.

\subsection{RESULTS}

The model is calculating the static conditions of pressure and temperature at every station of the engine, as well as the overall performance. The thermodynamic cycles of the different working fluids are analysed in this section. Additionally, a small variation analysis is conducted to examine the performance of the engine at slightly different operating conditions than at the design point. The impact of the inlet ram drag on the required fuel mass flow to achieve the targeted thrust, as well as the effect of the bypass duct on the overall performance are demonstrated. Due to the uncertainty in some parameters, an error propagation analysis is presented to evaluate the importance of accuracy in such variables. The integrated model is embedded into a multi-platform application where the concept is explained and the performance of the engine is made widely available. Finally, a preliminary cost analysis examines the market viability of a reusable launch vehicle, supported by the hybrid air-breathing rocket engines.

\subsection{Engine thermodynamic analysis}

In this section, the thermodynamic interactions of the working fluids of the engine are shown as produced by the model. This is very important for aircraft engines, since cycle analysis is necessary for both assessment and optimisation of the engine. The cycles of air, helium, as well as air in the bypass, are presented. Figure 4 illustrates the H-S diagram of the main cycle of the core engine.

This cycle depicts the thermodynamic processes of air and combustion products. As expected, at the beginning, air is compressed at the intake by two shock waves, increasing 


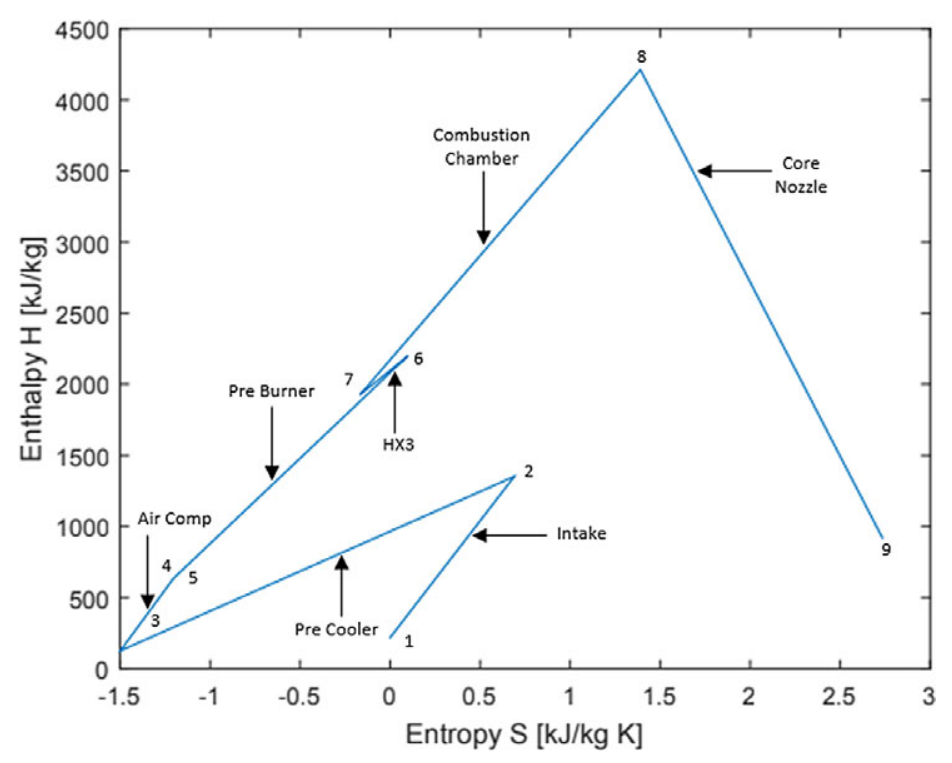

Figure 4. Core engine thermodynamic cycle.

the entropy of the system. The reason for the decrease in entropy is that inside the PC, helium extracts heat from air. This causes a huge increase in the entropy of helium cycle as shown in Fig. 5(a). Following the cooling process, air is compressed in the AirC and directed to $\mathrm{CC}$ for combustion. The diagram also shows the amount of air, diverted to the PB and HX3, before going to CC and finally expanded in the nozzle. Again, the decrease in entropy at HX3 is explained by the rise in entropy of the helium cycle at this component, as helium extracts heat from the hot PB combustion products.

Figure 5 illustrates the cycle of helium loop (a) and that of the airflow diverted to the bypass ramjet duct (b). The model calculation of the operating parameters of these cycles, produces a closed Brayton cycle for the helium loop and an open Brayton cycle for the bypass duct as expected for both cases, thus adding credibility to the model. As mentioned above, the cooling process at the PC creates a huge increase in the entropy of helium, which is presented as a decrease in the air-hydrogen loop. The same phenomenon is observed at the heat transfer process of HX3, since helium is extracting some heat from the airflow. The cycle analysis is an essential step in assessing the performance of an engine.

\subsection{Small variation analysis}

In order to examine which parameters have a significant impact on the results, a small variation analysis is conducted. The variables examined, among others, are the fuel-to-air ratio, flight Mach number and the PC outlet temperature of helium. This analysis is carried out for the core of the engine without accounting for the inlet ram drag.

Since the model is developed for the design point, it is only possible to investigate the behavior of the engine in a very close range of Mach 5, which is from Mach 4.8 to 5.2. Even in this Mach range, some working parameters slightly change (e.g. the altitude). However, small changes can be accepted in order to improve understanding of the engine operating principles. Figure 6 shows that a slightly less amount of liquid hydrogen is necessary when trying to achieve the same thrust, but flying with a higher Mach number. However, the impact on the 

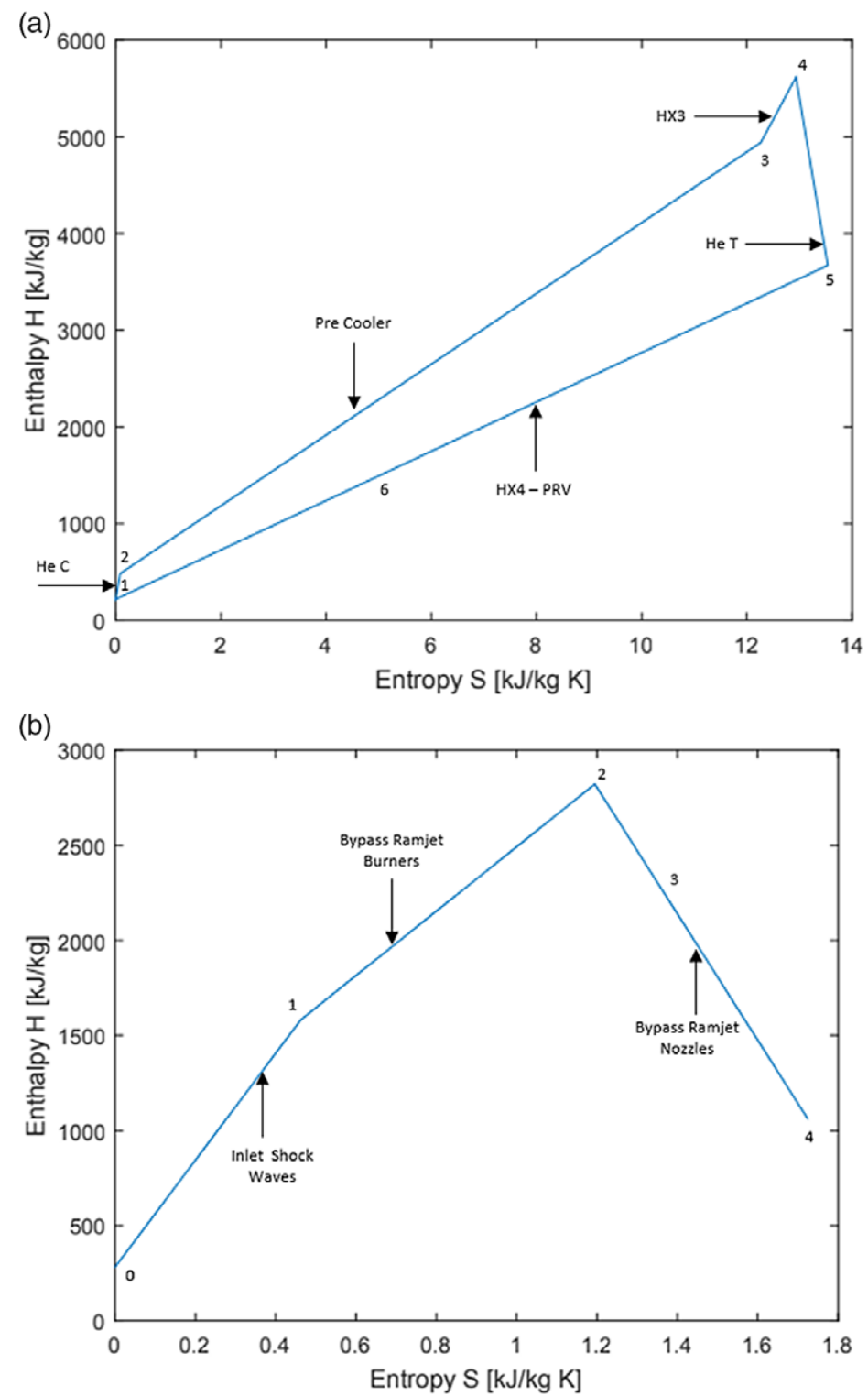

Figure 5. Thermodynamic cycles of: (a) Helium and (b) Bypass ramjet duct.

overall efficiency is not minor. That is because of the severe impact that the Mach number has on the propulsive efficiency, hence in the overall efficiency as well. This diagram demonstrates that fuel mass flow rate of the core engine changes slightly along the whole atmospheric ascent. The highlighted point refers to the design point of Mach 5, and its projections on the axes correspond to the values of hydrogen mass flow rate and overall efficiency of the core engine at this point.

The mass flow rate of hydrogen is connected to the mass flow rate of helium directly by Eq. (7). Thus, if less mass of helium could achieve the same cooling effects, this would improve the fuel efficiency, because the cycle would require less mass of liquid hydrogen. 


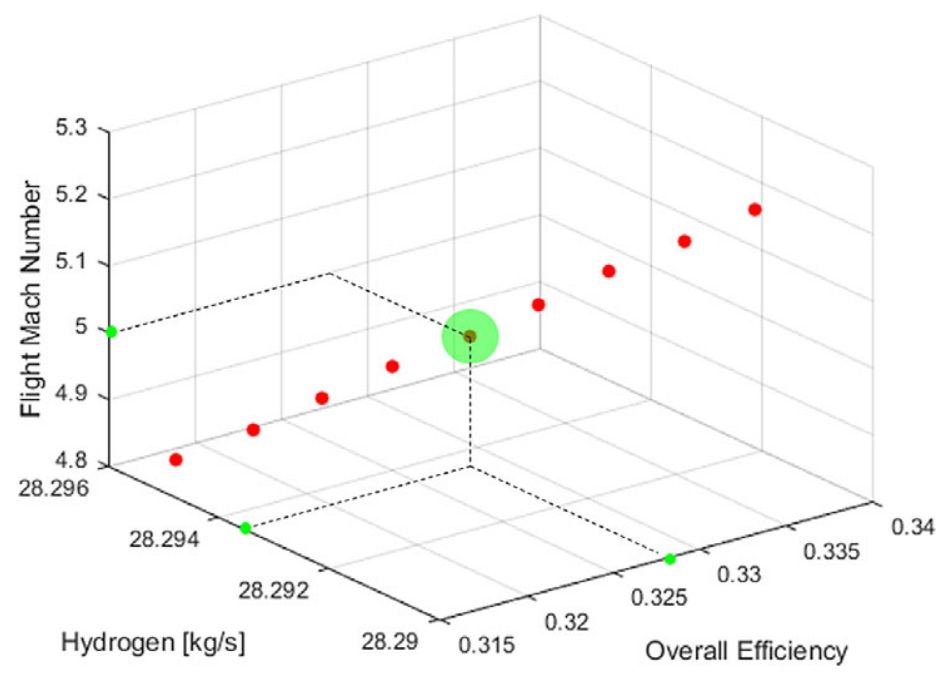

Figure 6. Variation of hydrogen mass flow rate and overall efficiency with flight Mach number.

Equation (7) is based on ideal energy transfer, and a heat-exchanger design limitation factor should be used in future work to reflect more accurate and realistic conditions.

$$
\dot{Q}_{H e}=\dot{Q}_{H_{2}} \Rightarrow \dot{m}_{H e} \cdot C_{p_{H e}} \cdot\left(\Delta T_{H e}\right)_{H X 4}=\dot{m}_{H_{2}} \cdot C_{p_{H_{2}}} \cdot\left(\Delta T_{H_{2}}\right)_{H X 4}
$$

Figure 7(a) illustrates the potential improvement in SFC, provided that the temperature limitation of $950 \mathrm{~K}$ of helium PC outlet temperature could be increased to a higher value. An increase of $40 \mathrm{~K}$ would result in approximately $9 \%$ improvement in SFC. The limitation comes from the selected material for the helium tubes in the PC. Additionally, Fig. 7(b) shows the impact of fuel-to-air ratio on the propulsive, thermal and overall efficiency of the core engine. As expected, fuel-to-air ratio is the major influencing factor of the engine thermodynamic performance. A reduction in fuel-to-air ratio from 0.09 to 0.07 advances the thermal efficiency by approximately $12 \%$, but propulsive efficiency changes slightly. This is because thermal efficiency is strictly connected to the fuel mass flow rate, while propulsive efficiency is a correlation between exit and flight velocity, both changing slightly with fuel-to-air ratio. Although a combined cycle engine is more complicated, it behaves similarly to air-breathing aircraft engines.

\subsection{Effect of inlet ram drag and bypass ramjet duct}

The impact of both the inlet ram drag and the bypass duct on the performance and operation of the engine is examined because it is expected to have a major effect at hypersonic flight speeds. Figure 8(a) presents the effect of inlet ram drag on the fuel mass flow rate of hydrogen required to achieve the targeted thrust. The investigation presented here for the inlet ram drag effect, is based on the core model, without accounting for the bypass duct. The inlet ram drag term is calculated directly by Eq. $(8)^{(2)}$. The required hydrogen mass flow rate to achieve a certain thrust value is calculated when neglecting the ram drag term and when considering it.

$$
D_{\text {ram }}=\dot{m}_{\text {core }} \cdot V_{\text {inf }}
$$



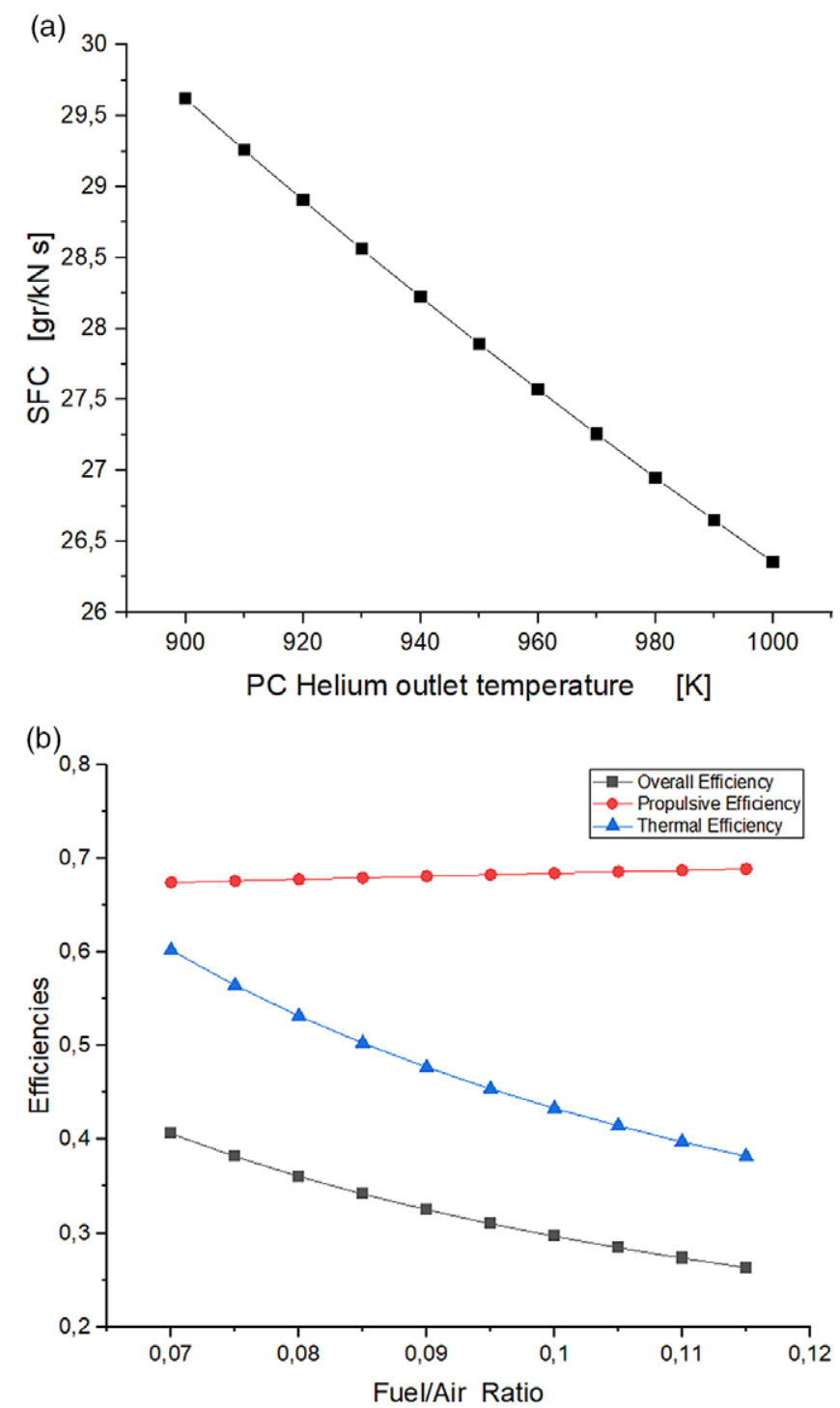

Figure 7. Variation of: (a) SFC with helium PC outlet temperature and (b) Efficiencies with fuel-to-air ratio.

The ram drag induced by the air at the intake has a significant effect on the operation of the engine (Fig. 8(a)). The targeted net thrust is the same for both cases. The required mass flow rate of liquid hydrogen is almost doubled when accounting for the inlet ram drag. Moreover, it is important to notice the trend of the diagram. As the targeted net thrust is getting higher, the impact of the inlet ram drag is getting more and more intense. The inlet ram drag in hypersonic systems is important because the increase in thrust is equivalent to an increase in flight Mach number.

Figure $8(\mathrm{~b})$ presents the effect of the bypass modeling, on the core engine model, in terms of the impact on the overall efficiency of the engine. The addition of the bypass in the core model, improves the overall efficiency of the engine by $7 \%$. This is mainly due to the increase 

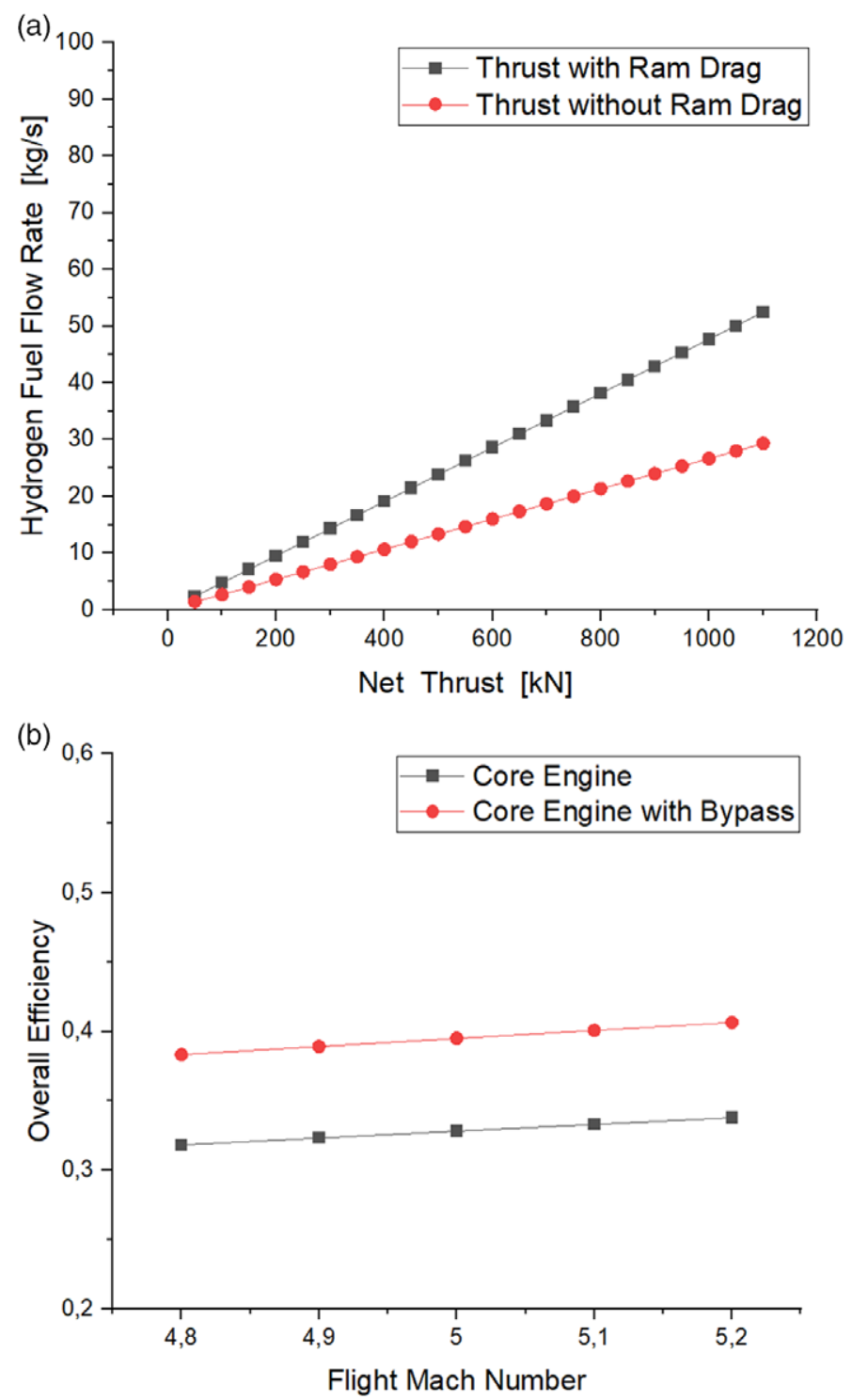

Figure 8. Impact of: (a) Inlet ram drag on fuel mass flow rate and (b) Bypass ramjet duct on the overall efficiency.

in the airflow while the required fuel mass flow rate is slightly higher. Thus, more thrust is produced with no major increase in fuel consumption. The bypass ramjet duct, as calculated in this study, produces approximately $20 \%$ of the thrust at the design point.

\subsection{Error propagation analysis}

Given the fact that the concept of the hybrid air-breathing rocket engine is still under development, there is some uncertainty surrounding several operating parameters of the model. An error propagation analysis is conducted, in order to examine the effect of this uncertainty 
on the overall performance of the engine. The selected parameters for this analysis, are the ambient pressure and temperature, and the heat capacity ratio $\gamma$ of gas at the CC.

\subsubsection{Method}

The overall uncertainty of a system can be calculated by examining the logarithmic derivative of the equation relating the unknown quantity to the known variables ${ }^{(36)}$. A maximum possible uncertainty can then be computed by summing the appropriate uncertainty terms. This approach also allows to verify the importance of each uncertainty term and is described by Eq. (9).

$$
\delta f=\left\{\left[\left(\frac{\partial f}{\partial x}\right) \cdot \delta \chi\right]^{2}+\left[\left(\frac{\partial f}{\partial y}\right) \cdot \delta y\right]^{2}+\left[\left(\frac{\partial f}{\partial z}\right) \cdot \delta z\right]^{2}+\ldots\right\}^{\frac{1}{2}}
$$

where $f$ is any function under investigation and $\delta$ is the error of each uncertainty term.

This analysis is conducted only for the core engine model. This is because the integrated model is more complicated, and it would only impose complexity in the calculations without improving understanding of the error propagation behaviour.

\subsubsection{Results and discussion}

Equation (9) is applied to calculate the error of the air temperature after the normal shock wave $T_{2}$ based on the error of ambient temperature using Eq. (1-3). The error in helium mass flow rate is calculated, based on the previous error in $T_{2}$, by using the energy conservation equation between air and helium at the PC, which is described by Eq. $(10)^{(44)}$.

$$
\dot{Q}_{A i r}=\dot{Q}_{H e} \Rightarrow \dot{m}_{A i r} \cdot C_{p_{A i r}} \cdot\left(\mathrm{T}_{2_{A i r}}-\mathrm{T}_{3_{A i r}}\right)_{P C}=\dot{m}_{H e} \cdot C_{p_{H e}} \cdot\left(\mathrm{T}_{3_{H e}}-\mathrm{T}_{2_{H e}}\right)_{P C}
$$

Additionally, the error in the air pressure after the normal shock wave $P_{2}$ is calculated based on the error of ambient pressure, using Eq. (1-3). The error in efficiencies is calculated based on the error of heat capacity ratio $\gamma$ in the $\mathrm{CC}$ as shown in Table 1. The Variable Errors shown in Table 1 are based on differences between several literature values ${ }^{(34,46)}$. The results are as follows:

$$
\begin{gathered}
\left\{\begin{array} { l } 
{ \frac { \delta \mathrm { T } _ { a m b } } { T _ { a m b } } = \pm 0 . 0 1 8 [ \% ] } \\
{ \frac { \delta P _ { a m b } } { P _ { a m b } } = \pm 0 . 3 8 [ \% ] }
\end{array} \Rightarrow \left\{\begin{array}{l}
\frac{\delta \dot{m}_{H e}}{m_{H e}}= \pm 0.02[\%] \\
\frac{\delta P_{2}}{P_{2}}= \pm 0.39[\%]
\end{array}\right.\right. \\
\frac{\delta \gamma}{\gamma}= \pm 0.41[\%] \Rightarrow\left\{\begin{array}{l}
\frac{\delta \eta_{t h}}{\eta_{t h}}= \pm 1.41[\%] \\
\frac{\delta \eta_{p}}{\eta_{p}}= \pm 0.03[\%] \\
\frac{\delta \eta_{o}}{\eta_{o}}= \pm 0.97[\%]
\end{array}\right.
\end{gathered}
$$

Equation (11) shows that an error in ambient temperature or pressure, gives approximately the same error in the calculation on the mass flow rate of helium or pressure after the normal shock wave, respectively. The equations relating those terms are linear, thus the propagation of the initial error is minimised. On the other hand, Eq. (12) shows that an error of about $0.4 \%$ 
Table 1

Estimation of errors in selected parameters

$\begin{array}{cccc}\text { Parameter } & \text { Value } & \text { Variable Error } & \boldsymbol{\delta} \mathbf{x} / \mathbf{x}[\%] \\ \mathrm{T}_{\mathrm{amb}}[\mathrm{K}] & 216.65 & 0.04 & 0.018 \\ \mathrm{P}_{\mathrm{amb}}[\mathrm{bar}] & 0.025273 & 0.0001 & 0.38 \\ \gamma[-] & 1.22 & 0.005 & 0.41\end{array}$

Table 2

Engine performance at design point

$\begin{array}{cccc}\text { Parameter } & \text { Model } & \text { Data } & \text { Error } \\ \text { Isp [s] } & 1832 & 1838 & 0.32[\%] \\ \eta_{\mathrm{p}}[\%] & 69.3 & - & - \\ \eta_{\mathrm{th}}[\%] & 57.14 & - & - \\ \eta_{\mathrm{o}}[\%] & 39.6 & - & - \\ \mathrm{SFC}[\mathrm{gr} / \mathrm{kN} / \mathrm{s}] & 55.7 & - & - \\ T_{\text {in }} P C[K] & 1217.8 & 1223 & 0.5[\%] \\ T_{\text {out }} P C[K] & 122 & 123 & 0.8[\%]\end{array}$

in the heat capacity ratio, results to an overall error of $1.4 \%$ in thermal efficiency, which is over three times higher. The error of propulsive efficiency is very low, because the final value is a correlation between the squared values of flight and gas exit velocities. This results to an overall uncertainty of about $1 \%$ in efficiency. The large uncertainty produced in the overall efficiency is caused by the exponential nature of the equations calculating the performance of the engine (e.g. Exit Mach number, Exit temperature).

This analysis demonstrates the importance of accuracy in some parameters of the model. It is essential to select the correct values of some key parameters such as the heat capacity ratio $\gamma$ in order to calculate the results more accurately. In addition, the error propagation to the final variable is determined by the nature of the equations involved. Finally, this analysis illustrates the difficulties in developing a model for off-design point operation, since much more uncertainties will rise.

\subsection{Model evaluation}

Table 2 provides several key parameters, as produced by the model, describing the performance of the engine at the design point in comparison with available data in the literature. The compared values include the engine specific impulse ${ }^{(1,8,9)}$, as well as air inlet and outlet temperatures from the $\mathrm{PC}^{(35,47)}$. As shown in Table 2, the developed component-level model is in good agreement with the data available in the literature, with a maximum error of $0.8 \%$. The values of Table 2 are the results of the integrated model, including the inlet ram drag.

At the design point, the output of the model for the specific impulse of the engine is $1832 \mathrm{~s}$. This is slightly lower than the J-58 turbojet engine of SR-71 cruising at Mach 3.2 and 4 times higher than most chemical rockets. The overall efficiency of the engine is approximately $40 \%$. 


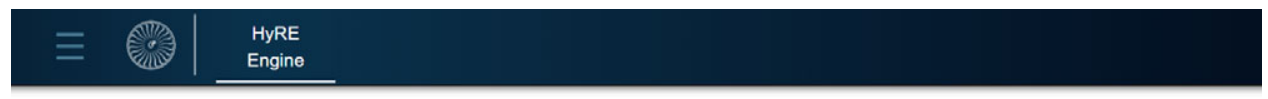

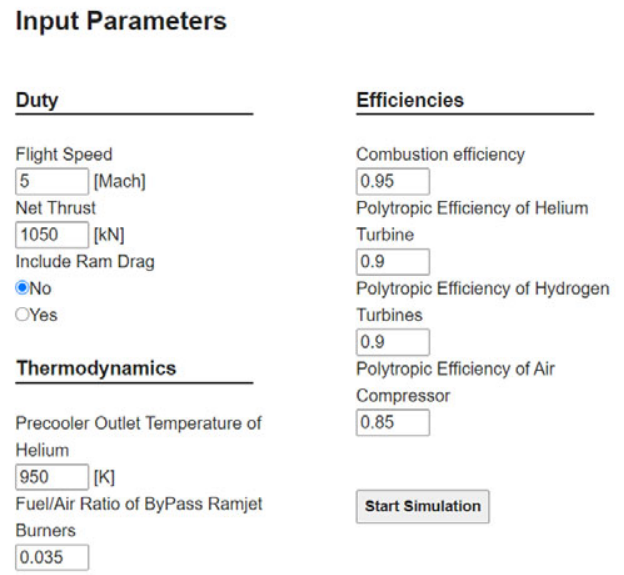

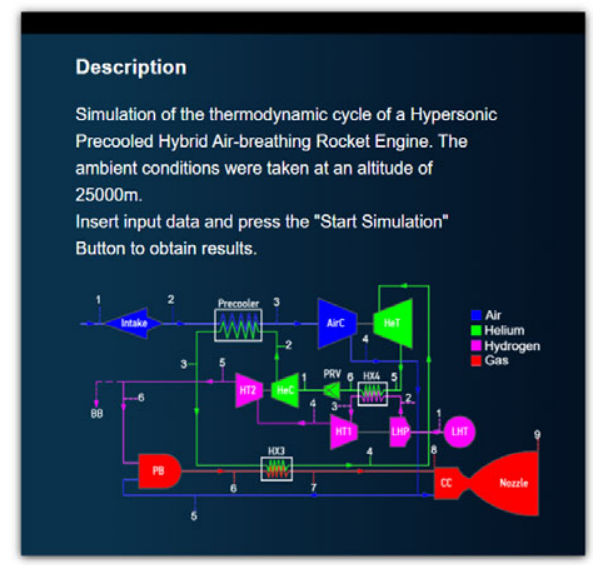

Figure 9. Input parameters template for hybrid air-breathing rocket engine as found in AeroEngineS application.

\subsection{The multi-platform application AeroEngineS}

The multi-platform application "AeroEngineS", which stands for "AeroEngine Simulation", has been developed at Aristotle University of Thessaloniki. Its main goal is to simulate the performance of aeroengines, in terms of calculating several working conditions of the engines ${ }^{(37)}$. The application is calculating the mass flows of the working fluids, pressures and temperatures at each station of the engine, as well as the performance parameters such as thrust, efficiencies, SFC, etc. Additionally, there are templates available for the calculation of aircraft emissions at different flight conditions, the prediction of compressor map operating points, as well as the calculation of the distance between two airports. Hence, the application has a general use in several topics concerning the aviation field. "AeroEngineS" can be found online or as a mobile application, and it is constantly being updated and new templates, concerning several aeronautical topics, are being added ${ }^{(38)}$. This study resulted in the enrichment of the application with two more templates - one for the hybrid air-breathing rocket engine, and one for a ramjet engine - thus widening the range of the application into the supersonic and hypersonic propulsion field.

\subsubsection{Hybrid air-breathing rocket engine template}

The final model of the hybrid air-breathing rocket engine is converted to JavaScript and embedded into "AeroEngineS". Figure 9 shows the template of the hybrid air-breathing rocket engine as seen in the "AeroEngineS" application. A description provides an explanation of the main concept of the simulation as well as the schematic of the core engine cycle.

The user may alter the flight speed in a region near Mach 5, which is from 4.8 to 5.2, since the model is developed to operate at the design point. Also, the user has the option to include the ram drag induced by the intake, thus getting a picture of the effect of the ram drag on the performance of the engine. Several thermodynamic parameters can be changed as well, such as the PC outlet temperature of helium, the fuel-to-air ratio of the bypass burners 


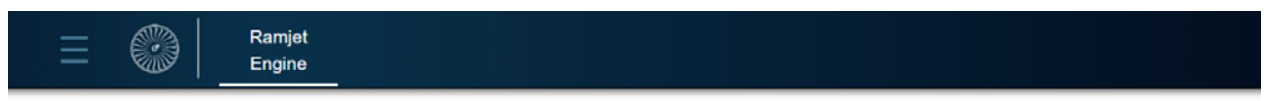

Input Parameters
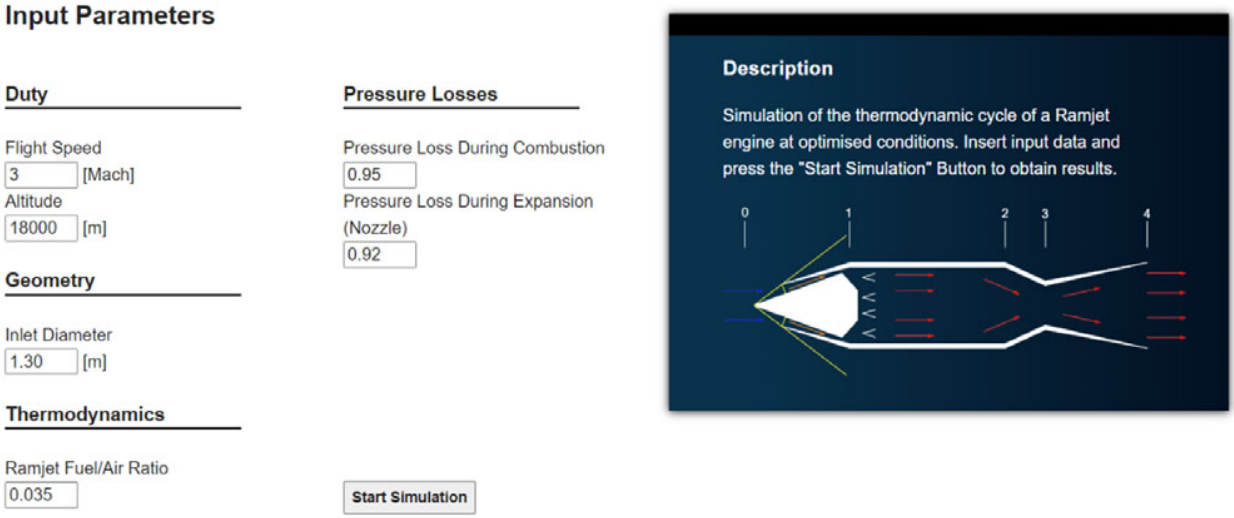

0.035

Start Simulation

Figure 10. Input parameters template for ramjet engine as found in AeroEngineS application.

and the efficiency of some components of the core engine. The user can thereby get a better understanding of the engine concept as well as examine the performance when altering several key parameters. Pressing the Start Simulation button, the user obtains the mass flow rates of each working fluid, the static pressures and temperatures at each station found in the cycle, and also the performance parameters of the engine.

\subsubsection{Ramjet engine template}

Based on the model initially developed for the bypass duct of the engine under investigation, a new template for a ramjet engine is added in the application. The user may change the flight speed and altitude, the inlet diameter of the engine, as well as several thermodynamic parameters. These include fuel-to-air ratio and efficiency, in terms of pressure drop, of the combustion and expansion process. The user obtains the same format of results as mentioned for the case of the hybrid air-breathing rocket engine. Figure 10 shows the input parameters template of the ramjet engine as seen in the application. A description provides an explanation of the main concept of the simulation as well as the schematic of the ramjet engine.

The schematics embedded in Figs. 9 and 10, correspond to the core engine cycle and the ramjet engine layout as found in Figs. 1 and 2, respectively.

\subsection{Preliminary cost analysis of an RLV}

For the completion of this study, a preliminary cost analysis is conducted to evaluate the market viability of an RLV. The selected vehicle is an aircraft-like spaceplane, using two of the engines under investigation. This study is mainly based on data available in the literature, and the main goal is to examine the conditions under which a concept like this could be viable or even profitable for the investor.

In space industry, the manufacturer is also the operator in most cases. This is found to be the main problem for the case of an RLV because of its large research and development costs. Space launches are expected to increase exponentially in the future, which makes the concept 


\section{Table 3}

\section{Cost of several space transportation systems}

$\begin{array}{lcccc}\text { System } & \begin{array}{c}\text { Payload to } \\ \text { LEO [kg] }\end{array} & \begin{array}{c}\text { Cost per } \\ \text { Launch }[\mathbf{M}]\end{array} & \begin{array}{c}\text { Cost per kg of } \\ \text { payload [/kg] }\end{array} & \text { Reference } \\ \text { Saturn V } & 130000 & 743 & 5715,4 & \mathrm{NASA}^{(40)} \\ \text { Space Shuttle } & 29000 & 600 & 20689,6 & \mathrm{NASA}^{(41)} \\ \text { Falcon 9 } & 22800 & \text { 62-expendable } & 2719,3 & \mathrm{SpaceX}^{(42)} \\ \text { Falcon Heavy } & 63800 & \text { 150-expendable } & 2351,1 & \text { SpaceX }^{(42)} \\ \text { RLV fleet: 1 } & 15000 & 40 & 2667 & \text { REL }^{(39)} \\ \text { RLV fleet: 5-10 } & 15000 & 10 & 667 & \text { REL }^{(39)}\end{array}$

more appealing. A comparison with other space systems is essential for the results. Table 3 provides the cost of several space transportation systems, as well as the expected cost of the RLV based on literature data ${ }^{(39)}$. The acquisition cost of the RLV used in this study, including the research and development costs, is approximately 18 billion $\$^{(13)}$.

In this analysis, the concept is examined from six different perspectives, and conclusions are drawn. The main factors examined are the stakeholders, the motivation, the upcoming demand in space market, the degree of reusability (e.g. a spaceplane with no upper stage is $100 \%$ reusable), the fleet number and, finally, the size of the spaceplane itself ${ }^{(43)}$.

Based on the data in the available literature as well as in Table 3, the following conclusions are drawn for the market viability of an RLV:

i. The viability of an RLV on entry into service, is not assured, mainly due to the huge acquisition cost required, from a single operator.

ii. The cost per launch could lower to 40 million with one operational RLV and to 10 million with a fleet of 5-10, thus generating even more space launches.

iii. The cost per kilogram of payload into orbit might be an important factor of comparison between space transportation systems, but it is not the most critical, mainly because of its connection to the size of the system.

iv. Space launches are expected to increase in the next years, hence an RLV will become much more suitable to serve the demand.

v. A concept like this would probably need several public and private subsidies before being able to become viable, even with the predicted increase in the space launches.

vi. A different approach of the space market, similar to that of the civil aviation industry, where a manufacturer constructs the RLV and sells it to several operators, seems much more viable for this concept and able to address the big acquisition cost problem.

\subsection{CONCLUSIONS AND FUTURE WORK}

A thermodynamic analysis and simulation of a hybrid air-breathing rocket engine has been presented. This is facilitated through the development of a component-level, app-embedded model, including both the core engine and the bypass duct. The operation of the engine, at 
the design point of Mach 5 and altitude of $25 \mathrm{~km}$, is analysed. The main conclusions are as follows:

- In this analysis the thermodynamic cycles of air and helium in the core as well as the air in the bypass are presented. The operating principles of the engine are thereby demonstrated. This is essential for the improvement of cycle efficiency and optimisation of the engine.

- The small variation analysis has shown that an increase of $40 \mathrm{~K}$ of the helium PC outlet temperature may result in an improvement of approximately $9 \%$ in SFC. Thus, the significance of the heat exchanger design for the overall engine efficiency is demonstrated. Fuel-to-air ratio is found to be the main influencing factor of the engine performance.

- An error propagation analysis reveals that an initial uncertainty of $0.4 \%$ in the heat-capacity ratio of the combustion chamber leads to an error of approximately $1.4 \%$ in the thermal efficiency. Thus, the importance of some key parameters on the final performance results is outlined.

- The developed model for the hybrid air-breathing rocket engine is embedded into a multiplatform application. The concept of the engine is explained. The effect of the inlet ram drag and other key working parameters on the engine performance, is made widely available. Hypersonic flight using precooled combined cycle engines is thereby exposed to the interested reader.

- Market viability of a reusable launch vehicle is examined through a preliminary cost analysis. This is found to be depending on several factors, owing to the huge acquisition cost, and becomes viable only under certain conditions. These include several public or private investments and a totally different approach to the space market similar to the civil aviation industry.

- The inlet ram drag has a significant impact on the engine performance at hypersonic speeds, thus it should not be neglected in the modeling. The results on the engine performance show good agreement with data found in the open literature, with a maximum calculation error of $0.8 \%$.

- The bypass duct produces approximately $20 \%$ of the targeted net thrust of the engine at the design point, as calculated by the model. It also improves the overall efficiency by $7 \%$, thus it is a very important factor for the modeling and should not be neglected.

- The model calculates the specific impulse of the engine at approximately $1800 \mathrm{~s}$, which is about 4 times higher than any chemical rocket. This engine concept is the most suitable for a single-stage-to-orbit mission, and advantageous in numerous other applications.

Currently, the enrichment of the model with added functions is under development in order to evaluate the off-design point performance of the engine. Additionally, future work will be focused on developing a transient model to simulate the whole atmospheric ascent, based on the existing model for the design point. The multi-platform application will be updated with the latest changes.

\section{REFERENCES}

1. VARVILL, R. and Bond, A. A comparison of propulsion concepts for SSTO reusable launchers, J Br Interplanet Soc, 2003, 56, pp. 108-117.

2. Farokhi, S. Future Propulsion Systems and Energy Sources in Sustainable Aviation, 2019.

3. Roberts, N.K. and Wilson, R.D. Analysis and design of a hypersonic scramjet engine with a transition mach number of 4.00, AIAA 2009-1255, 2009. doi: 10.2514/6.2009-1255 
4. Srinivasan, K., Maurya, P.K., Abhishek, K., Desikan, S.L.N. and Murugan, B. Supersonic combustion of a scramjet engine using hydrogen fuel in shock tunnel, AIAA, 2018. doi: 10.2514/1.J056761

5. HeIser, W.H. Hypersonic Airbreathing Propulsion, American Institute of Aeronautics and Astronautics, 1994, Washington, DC, USA, ISBN 1563470357.

6. Cumpsty, N.A. Jet Propulsion: A Simple Guide to the Aerodynamic and Thermodynamic Design and Performance of Jet Engines, 2e. Cambridge, UK, 2003.

7. JiAN, D. and QIURU, Z. Key technologies for thermodynamic cycle of precooled engines: a review, Acta Astronaut, 2020, 177, pp. 299-312.

8. Verstraete, D and Hendrick, P. Hydrogen Fueled Precooled Airbreathing Engines for Hypersonic Aircraft and Spaceplanes, ISABE-1329, 2011.

9. Webber, H., Bond, A. and Hempsell, M. The sensitivity of precooled air-breathing engine performance to heat exchanger design parameters, $J$ Br Interplanet Soc, 2007, 60, pp. 188-196.

10. Webber, H., Feast, S. and Bond, A. Heat Exchanger Design in Combined Cycle Engines, IAC $08-$ C4.5.1.

11. Longstaff, R. and Bond, A. The SKYLON Project, AIAA 2011-2244, 2011.

12. Hempsell, M. A phased approach to orbital public access, Acta Astronaut, 2010, 66, pp. 1639-1644.

13. Hempsell, M., Aprea, J., Gallagher, B. and Sadlier, G. A business analysis of a SKYLON-based European launch service operator, Acta Astronaut, 2016, 121, pp 1-12.

14. HemPSell, M. Space Stations Using the SKYLON Launch System, IAC-10.B3.7.3.

15. Hempsell, M. and Bond, A. SKYLON: an example of commercial launcher system development, $J$ Br Interplanet Soc, 2014, 67, pp. 434-439.

16. Cecere, D., Giacomazzi, E. and Ingenito, A. A review on hydrogen industrial aerospace applications, Int J Hydrog Energy, 2014, 39, pp. 10731-10747.

17. VARVILL, R. and Bond, A. The SKYLON spaceplane - progress to realisation, $J$ Br Interplanet Soc, 2008, 61, pp. 412-418.

18. Hempsell, M. An analysis of the SKYLON infrastructure, IAC - 09.D3.3.4, 2009.

19. Hempsell, M., Bond, R., Longstaff, R. and Varvill, R. The SKYLON D1 configuration, IAC 10.D2.4.7., 2010.

20. Hempsell, M. Progress on SKYLON and SABRE, IAC-13, D2.4, 6x19609, 2013.

21. Varvill, R., Duran, I., KIRK, A. and LANGridge, S. SABRE Technology development: Status and Update, $8^{\text {th }}$ European Conference for Aeronautics and Space Sciences, EUCASS, 2019, p. 307, doi: 10.13009

22. Waugh, I., Davies, A., Moore, E., Webber, H. and Macfarlance, J. Testing Air-Breathing Rocket Engines, SP2016 3125048, 2016.

23. Jivraj, F., Varvill, R., Bond, A. and Paniagua, G. The Scimitar Precooled Mach 5 Engine, $2^{\text {nd }}$ European Conference for Aerospace Sciences, EUCASS, 2007.

24. SzIroczak, D. and Smith, H. A review of design issues specific to hypersonic flight vehicles, Prog Aerosp Sci, 2016, 84, pp. 1-28.

25. Wang, Z.G., Wang, Y., Zhang, J.Q. and Zhang, B.C. Overview of the key technologies of combined cycle engine precooling systems and the advanced applications of microchannel heat transfer, Aerosp Sci Technol, 2014, 39, pp. 31-39.

26. Villace, V.F. and Paniagua, G. Numerical model of a variable-combined-cycle engine for dual subsonic and supersonic cruise, Energies, 2013, 6, pp. 839-870.

27. Nehemiah, J.W. A Performance Analysis of a Rocket Based Combined Cycle (RBCC) Propulsion System for Single-Stage-To-Orbit Vehicle Applications, Master Theses, 2010.

28. Villace, V.F. and Paniagua, G. Simulation of a combined cycle for high speed propulsion, in: 48th AIAA Aerospace Sciences Meeting Including the New Horizons Forum and Aerospace Exposition, Orlando, Florida, AIAA 2010-1125, 2010.

29. Jiangiang, Z., Zhenguo, W. and Qinglian, L. Thermodynamic efficiency analysis and cycle optimization of deeply precooled combined cycle engine in the air-breathing mode, Acta Astronaut, 2017, 138, pp. 394-406. doi: 10.1016/j.actaastro.2017.06.011

30. Amati, V., Bruno, C., Simone, D. and Sciubba, E. Exergy analysis of hypersonic propulsion systems: performance comparison of two different scramjet configurations at cruise conditions, Energy, 2008, 33, pp. 116-129. 
31. Chang, J.T., Cao, S.B., Zhang, J.L., Z, J.F., Bao, W., S, W.Q. and Li, Z.X. Effects of air Vitiation on scramjet performance based on thermodynamic cycle analysis, JAAE Open Access, 2014, 3, pp. $1-7$.

32. Reaction Engines Limited, The SABRE Engine, accessed at: 16/12/2020, URL https://www.reactionengines.co.uk/beyond-possible/sabre

33. SKYLON User's Manual, SKY-REL-MA-0001, Rev 2, May 2014.

34. ANDERson, J.D. Jr. Fundamentals of Aerodynamics, 5th ed, McGraw-Hill, 2017, New York. ISBN 9780073398105.

35. VARVILL, R. Heat Exchanger Development at Reaction Engines LTD, IAC-08-C4.5.2, 2008.

36. Ku, H.H. Notes on the use of propagation of error formulas, J Res Natl Bur Stand, 1996, 70C, (4), pp. 263-273.

37. Pontika, E., Kalfas, A. and Aslanidou, I. AeroEngineS: Multi-Platform Application for Aero Engine Simulation and Compressor Map Operating Point Prediction, ASME, Turbomachinery Technical Conference and Exposition, November, 2019.

38. AeroEngineS web application, accessed at: 16/12/2020, Aggelos Gaitanis, Evangelia Pontika, Spyros Tsentis, Maria Bakali, Anestis Kalfas, URL http://aes.propulsion.gr/

39. Hempsell, M. and Longstaff, R. The requirement generation process for the SKYLON launch system, J Br Interplanet Soc, 2010, 63, pp. 112-128.

40. MAY, S. What was the Saturn V, NASA knows! (Grades 5-8), 2017.

41. NASA, The Space Shuttle and its Operations, accessed at: 16/12/2020, URL https://www. nasa.gov/centers/johnson/pdf/584722main_Wings-ch3a-pgs53-73.pdf

42. SpaceX, Capabilities \& Servicies, accessed at 16/12/2020, URL https://www.spacex.com/ media/CapabilitiesServices.pdf

43. Webi, R. Is it Worth it? The economics of Reusable Space Transportation, ICEAA 2016 International Training Symposium, Bristol, UK, October, 2016.

44. Cengel, A.Y., Boles, A.M. Thermodynamics: An Engineering Approach, 8th ed, McGraw-Hill, 2014, New York. ISBN 9780073398174.

45. Cohen, H., Rogers, G.F.C., Straznicky, P.V., Saravanamuttoo, H.I.H. and Nix, A. Gas Turbine Theory, 7 th ed.

46. NASA, Earth - Atmosphere Model, accessed at: 16/12/2020, URL https://www.grc.nasa. gov/WWW/K-12/airplane/atmosmet.html

47. Borg, K. and Matula, E. The SKYLON Spaceplane, 2015, University of Colorado, Boulder, CO, 80309, USA, ASEN 5053 - Rocket Propulsion. 